\title{
Epidemiological Pattern of Acute Pediatric Poisoning in Mashhad, Iran During 2011 - 2013
}

\author{
Anahita Alizadeh, ${ }^{1}$ Masoumeh Zheani Asoudeh, ${ }^{2}$ Fatemeh Abdi, ${ }^{2}$ Mohammad Moshiri, ${ }^{3,4}$ Mahdi Balali \\ Mood, ${ }^{5}$ and Leila Etemad ${ }^{6, *}$ \\ ${ }^{1}$ Pediatrician, Fellowship of Clinical Toxicology, Imam Reza Hospital Mashhad, Mashhad University of Medical Sciences, Mashhad, IR Iran \\ ${ }^{2}$ Faculty of Medicine, Mashhad University of Medical Sciences, Mashhad, IR Iran \\ ${ }^{3}$ Legal Medicine Research Center, Legal Medicine Organization, Tehran, IR Iran \\ ${ }^{4}$ Medical Toxicology Research Centre, Faculty of Medicine, Mashhad University of Medical Sciences, Mashhad, IR Iran \\ ${ }^{5}$ Medical Toxicology Research Centre, Imam Reza Hospital, Faculty of Medicine, Mashhad University of Medical Sciences Mashhad, IR Iran \\ ${ }^{6}$ Pharmaceutical Research Center, Mashhad University of Medical Sciences, Mashhad, IR Iran \\ "Corresponding author: Leila Etemad, Pharmaceutical Research Center, Mashhad University of Medical Sciences, Mashhad, IR Iran. Tel: +98-5138823255, Fax: +98-5138823251, \\ E-mail: etemadl@mums.ac.ir
}

Received 2015 October 20; Revised 2016 April 22; Accepted 2016 November 05.

\begin{abstract}
Background: Poisoning is dangerous and common in children. We evaluated the epidemiological pattern of acute pediatric poisoning and its recent changes in Mashhad.

Objectives: The current study aimed to evaluate the epidemiological pattern and recent changes of APP in Mashhad city during 2011- 2013.

Patients and Methods: This cross sectional/descriptive study was performed based on the data (including age, sex, home address, and diagnosis) recorded in the hospital information system (HIS) regarding children admitted to pediatric toxicology unit of Imam Reza Hospital, the only referral hospital in Mashhad, during 2011 - 2013.

Results: Over the three years, 1701 children (53\% male) aged $60.57 \pm 1.95$ months were hospitalized. The number of acutely poisoned children (APC) and the proportion of APC to the total number of pediatric admissions were 519 (14.1\%) in 2011, 472 (13.5\%) in 2012, and $710(18.1 \%)$ in 2013 ( $\mathrm{P}<0.0001)$. However, the pediatric to adult poisoning ratio (9.7\%, 8.9\%, and 8.5\%) did not change significantly (P $=0.0561)$ over the years. The APC cases became older from $55.6 \pm 2.3$ months in 2011 to $70.0 \pm 2.7$ months in $2013(\mathrm{P}<0.0001)$. The leading cause of APC was opium (179) in 2011 that decreased to 117 in $2013(\mathrm{P}<0.0001)$, whereas the methadone induced APC raised from 144 to $252(\mathrm{P}=0.0303)$.

Conclusions: The number of APC increased in this area over the period of the study. The pattern of pediatric poisoning changed from a traditional opium poisoning to methadone overdose from 2011 to 2013 , which may be due to the changing pattern of addiction and increased availability of methadone in the houses of addicted parents.
\end{abstract}

Keywords: Epidemiology, Children, Intoxication, Methadone, Opium

\section{Background}

Acute pediatric Poisoning (APP) is common in the most countries $(1,2)$. More than 2 million APPs ( $<6$ years old) annually are reported to American association of poisoning control center (3). In recent years, opiate, anti-depressants and cardiovascular drugs have been the leading causes of poison-related fatalities in young children $(4,5)$. APP is a common problem in Mashhad city located in the North East of Iran. According to the unpublished recorded data over the recent years, 500 to 700 cases of APP have been annually admitted to pediatric toxicology unit of Imam Reza hospital (IRH), affiliated to Mashhad University of Medical Sciences (MUMS).

APP is one of the most common medical emergencies that comprise about $2.3 \%$ of all pediatric admissions $(6,7)$.
The incidence rate of APP is in rage of $0.74 \%$ to $7.6 \%(2,8)$ while the mortality rate is about 3\% - 5\% (9). APP is the fifth unintentional cause of death in children in Iran (10).

The pattern of APP may change over time and may follow various patterns in different parts of the world (6, 11). Epidemiological data, particularly changing pattern of APP, is required for health planning and prioritizing the financial resources (12).

\section{Objectives}

The study aimed to evaluate the epidemiological pattern and recent changes of APP in Mashhad city during 2011 - 2013. 


\section{Patients and Methods}

This cross sectional/descriptive study was performed on acutely poisoned children who admitted in pediatric toxicology unit of IRH, MUMS, Mashhad, Iran, between 2011 and 2013. The admitted children in IRH pediatric toxicology unit that were poisoned less than 24 hours earlier were included in the study. IRH pediatric toxicology unit of MUMS is the only pediatric toxicology ward in Mashhad; therefore, all APPs in the city are referred to this ward. Pediatric toxicology unit is a joint venture between the departments of clinical toxicology and pediatrics that was established in 2010. The academic clinical staff is provided by the clinical toxicology department (two pediatric toxicologists) and the clinical resident and nursing care are supported by the pediatric department.

The patients' information including age (in month), sex, type of poisoning, and residence addresses was collected based on the data recorded in the hospital information system (HIS).

Mashhad city has 13 municipal divisions (Figure 1). We summarized the patients' addresses based on the municipal divisions. We compared the children methadone poisoning rate based on the numbers of pediatric poisoning per one million citizens who live in each municipal division of Mashhad through 2011 - 2013, however, the fertility rates varied in different divisions of the city, as mentioned in limitations.

Statistical analysis of all variables was performed by using SPSS (version 11.5). A two-way repeated-measures ANOVA was used to evaluate differences in continuous numerical variables and means of different groups. Tukey ttest was performed as posttest. Kruskal-Wallis, ANOVA, and Mann-Whitney tests were used as appropriate. Fisher exact or $\chi^{2}$ tests were used to evaluate differences in sex rate and annual frequency. The alpha level was set at 0.05 .

\section{Results}

During 2011 - 2013, a total number of 1471 children (53\% male) aged $60.57 \pm 1.95$ months were hospitalized. The number of annual poisoning admissions was 519 in 2011, 472 in 2012, and 710 in 2013. The total number of APP admissions and the percentage of poisoning cases in the years 2011 to 2013 were 3699 (14.1\%), 3491(13.5\%), and 3920(18.1\%), respectively $(\mathrm{P}<0.0001)$. However, the proportion of APP to adult poisoning cases (9.7\%, 8.9\%, and 8.5\%) did not change significantly $(\mathrm{P}=0.0561)$ over the years (Table 1 ).

The sex ratio of the patients was unchanged over the years, however, the mean age of admitted poisoned children raised significantly $(\mathrm{P}<=0.0001)$ (Tables 2 and 3 ).
The youngest child was a 3 day old infant who was intoxicated by opium and the oldest one aged 168 months who had antidepressant drug overdose. All admitted children were discharged except one 18-month child who was intoxicated by methadone and expired.

The leading causes of APP during 2011 - 2013, were Opium, Methadone and Benzodiazepines (BZD) (Table 4). During 2011-2013, the frequency of opium $(\mathrm{P}<0.0001)$ and toxic plant poisonings $(\mathrm{P}=0.0015)$ decreased while the frequency of methadone $(\mathrm{P}=0.0303)$ and acetaminophen poisonings ( $P=0.0436)$ increased (Table 4$)$. In 2011 , the most common cause of APP was opium (34.5\%) in infants with mean age of $22.3 \pm 2.2$ months from whom, $55.4 \%$ were male, whereas methadone poisoning was the first rank in 2013 (35.5\% of total poisonings, infant's mean age of 52.2 \pm 3.2 months, $59.1 \%$ male). The frequency of overdose with other drug such as amphetamines and tramadol increased but not statistically significant (Table 4 ).

Due to the significant increase in the rate of pediatric methadone poisoning, we investigated the geographic residence based on patients' home address. The proportions of acute pediatric methadone poisoning to one million citizens living in each municipal division in Mashhad through 2011 - 2013 are summarized in Figure 1 and Table 5. The highest frequency of methadone-poisoned children was in the $13^{\text {th }}$ municipal division $(\mathrm{P}<0.0001)$. The frequency of methadone poisoned-children significantly decreased in the $1^{\text {st }}, 2^{\text {nd }}$ and $8^{\text {th }}$ municipal divisions, while it significantly increased in the $7^{\text {th }}$ municipal division.

\section{Discussion}

According to the results, increasing trend in the numbers of APP over the years 2011 - 2013 was evident (Table 1). Raising the number of APP and the proportion of APP to all pediatric admissions may be due to the availability of drugs or medicines at homes (13). The constant ratio of APP to adult poisonings despite the increasing numbers of APP may bring this idea to the mind that other factors could be involved in the raising numbers of total poisoning, adult poisoning, and APP $(14,15)$. The sex ratio $(53.1 \%$ male) of our cases did not change significantly over the period of the study, which was similar to the reports of Joghatae et al. (16) and Farnaghi et al. (17).

The number and pattern of APP have recently been changed in the region of the study. Similar changes have been reported from other regions (5). Socio-economic problems, lack of knowledge, introduction of new drugs and new formulations of pharmaceuticals, drug availability, demographic changes, and high rate of availability of drugs of abuse, and some new medical treatment pro- 


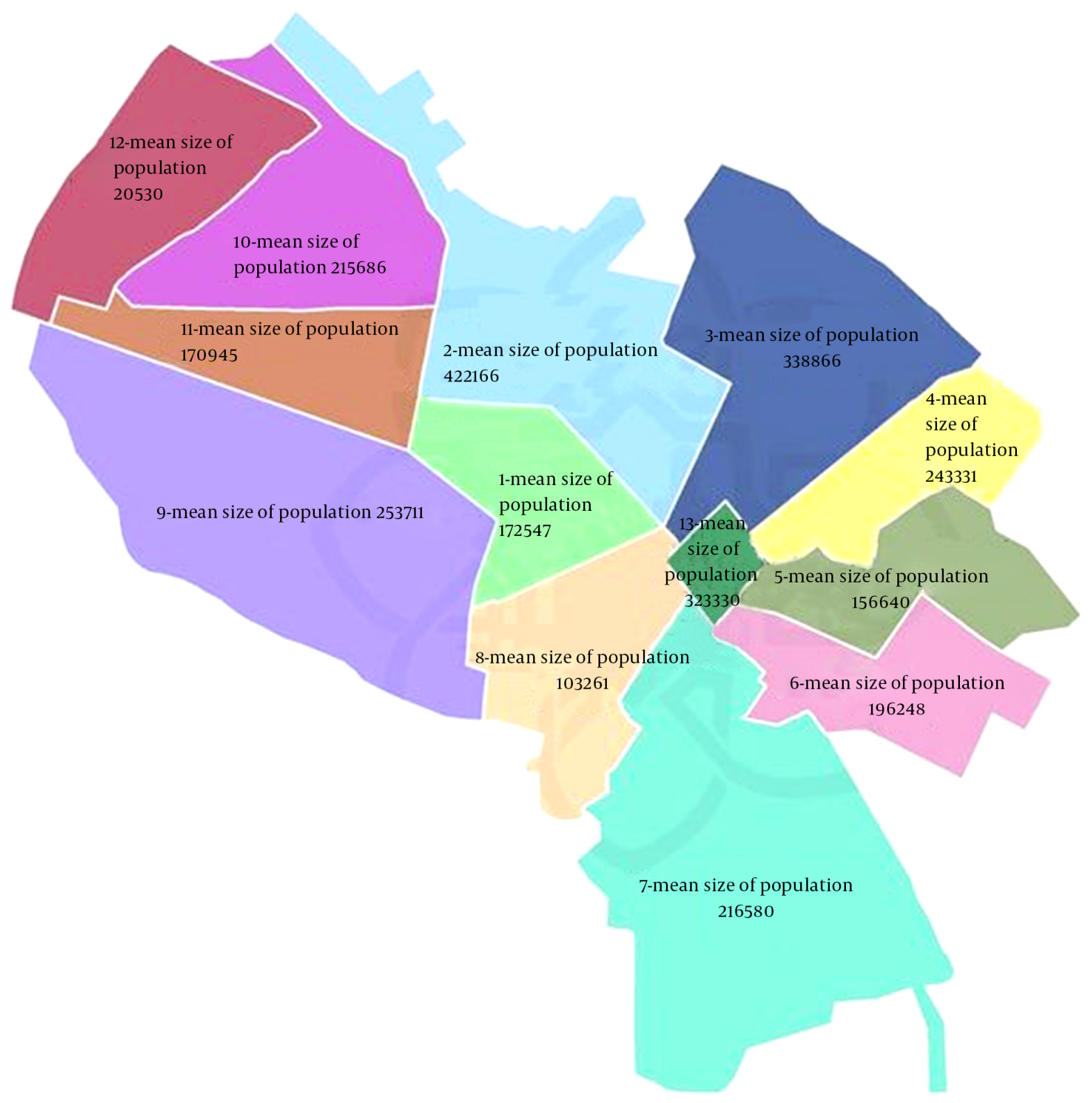

Figure 1. Thirteen Municipal Divisions of Mashhad and Mean Size of Population in Each Division

grams e. g., Methadone Maintenance Therapy (MMT), may be the causes of these changes $(1,14,18)$.

The mean age of poisoned children also resembles the mean age reported in some other studies $(16,19,20)$. However, in our study, the mean age significantly increased over the years of the study from 2011 to 2013 (Table 2); this trend may be due to the increased numbers of older children poisoned by methadone or the other medicines.

The most common causes of children poisonings in our study were related to Methadone, Opium, and Benzodiazepine, whereas in the report of Joghataee et al. (2001) (16), the most common causes of APP included hydrocarbon, opium, and pharmaceuticals. However, the most common pharmaceutical cause of poisoning in children, was attributed to Benzodiazepine (16).

Based on our results, it seems that the mean age of opium poisoned children was lower $(22.3 \pm 2.2$ months $)$ than the mean age of children poisoned with other types 
Table 1. Total Number of Poisoned Children and the Summary of $\chi^{2}$ Test Results for Comparison of Total Number of Pediatric Admissions and Adult Poisoning Admissions

\begin{tabular}{|c|c|c|c|c|}
\hline & 2011 & 2012 & 2013 & Pvalue \\
\hline Total number of children admitted to pediatric ward & 3669 & 3491 & 3920 & \\
\hline Total number of poisoned children admitted to pediatric toxicology unit & 519 & 472 & 710 & \\
\hline Percentage of poisoned children to total admitted children, (\%) & 14.14 & 13.52 & 18.11 & $<0.0001$ \\
\hline Total number of poisoned adults admitted to toxicological ward & 5319 & 5273 & 8301 & \\
\hline Percentage of poisoned children to total poisoned adults, (\%) & 9.7 & 8.9 & 8.5 & 0.0561 \\
\hline
\end{tabular}

Table 2. Summary of the Children Mean Age (in Month) Analysis Based on the Different Causes of Acute Pediatric Poisoning

\begin{tabular}{|c|c|c|c|c|}
\hline \multirow[t]{2}{*}{ Cause of Intoxication } & \multicolumn{3}{|c|}{ Mean Age \pm SD (Month) } & \multirow[t]{2}{*}{ PValue $^{\mathbf{a}}$} \\
\hline & 2011 & 2012 & 2013 & \\
\hline \multicolumn{5}{|l|}{ Opium and opiate } \\
\hline Total & $39.9 \pm 2.2$ & $43.3 \pm 2.3$ & $53.0 \pm 3.0$ & $0.0009^{b}$ \\
\hline Opium & $22.3 \pm 2.2$ & $23.6 \pm 2.4$ & $19.4 \pm 3.2$ & 0.731 \\
\hline Methadone & $54.7 \pm 3.3$ & $51.4 \pm 2.6$ & $52.2 \pm 3.2$ & 0.31 \\
\hline Buprenorphine & $24.0 \pm 3.1$ & $21.6 \pm 4.4$ & $34.0 \pm 5.0$ & 0.999 \\
\hline Tramadol & $78.6 \pm 12.4$ & $98.3 \pm 12.5$ & $113.2 \pm 9.7$ & 0.0977 \\
\hline \multicolumn{5}{|l|}{ Amphetamines } \\
\hline Total & $36.0 \pm 9.2$ & $49.5 \pm 13.5$ & $43.0 \pm 9.4$ & 0.779 \\
\hline \multicolumn{5}{|l|}{ Medicine } \\
\hline Total & 97.45 .6 & 84.65 .8 & 101.45 .0 & 0.1126 \\
\hline Acetaminophen & $102.3 \pm 14.2$ & $95.0 \pm 14.9$ & $131.1 \pm 11.8$ & 0.176 \\
\hline Tricyclic antidepressant & $68.5 \pm 12.4$ & $83.0 \pm 15.7$ & $121.3 \pm 13.5$ & $0.02^{\mathrm{b}}$ \\
\hline Benzodiazepine & $106.2 \pm 7.8$ & $79.1 \pm 7.3$ & $86.5 \pm 6.8$ & $0.038^{\mathrm{b}}$ \\
\hline Antipsychotic & $72.4 \pm 24.9$ & $80 \pm 49.0$ & $84.7 \pm 21.7$ & 0.878 \\
\hline Antihistamines & $125.1 \pm 19.0$ & $76.1 \pm 20.9$ & $101.6 \pm 14.2$ & 0.78 \\
\hline \multicolumn{5}{|l|}{ Others } \\
\hline Total & 86.18 .2 & 86.18 .17 & 101.413 .2 & 0.4944 \\
\hline Carboxyhemoglobin & $42.5 \pm 41.5$ & $94.0 \pm 19.1$ & $106.6 \pm 18.4$ & 0.609 \\
\hline Pesticide & $108 \pm 32.0$ & $88.0 \pm 47.2$ & $99.0 \pm 37.7$ & 0.938 \\
\hline Envenomation & $107.5 \pm 15.7$ & $93.9 \pm 10.1$ & $109.0 \pm 23.3$ & 0.757 \\
\hline Plant & $65.9 \pm 9.6$ & $72.0 \pm 106$ & $71.0 \pm 42.0$ & 0.917 \\
\hline \multicolumn{5}{|l|}{ Total } \\
\hline Total & $55.6 \pm 2.3$ & $55.0 \pm 2.2$ & $70.0 \pm 2.7$ & $0.0001^{\mathrm{b}}$ \\
\hline
\end{tabular}

${ }^{\text {a }}$ Data were analyzed by ANOVA test; Kruskal-Wallis, ANOVA, and Mann-Whitney tests were used as appropriate.

${ }^{\mathrm{b}}$ Statistically significant.

of poisons. It may be due to the parents' tendency to give opium to their children for treating diarrhea, cough, somnolence, and infantile colic, as well as due to accidentally ingestion of opium by children.

The mean age of methadone poisoned children in our study was similar to that reported from other hospitals in Iran $(17,21)$. Methadone is a synthetic $\mu$-opioid-receptor agonist that is used both for treatment of chronic pain and as methadone maintenance therapy (MMT) for opioid dependency (22). This opiate not only allows patients 
Table 3. The Frequency of Different Causes of Acute Pediatric Poisoning Based on Gender

\begin{tabular}{|c|c|c|c|c|}
\hline \multirow[t]{2}{*}{ Cause of Intoxication } & \multicolumn{3}{|c|}{ Male, $(\%)$} & \multirow[t]{2}{*}{ PValue $^{a}$} \\
\hline & 2011 & 2012 & 2013 & \\
\hline \multicolumn{5}{|l|}{ Opium and opiate } \\
\hline Total & 56 & 57 & 54 & 0.843 \\
\hline Opium & 55 & 57 & 59 & 0.836 \\
\hline Methadone & 60 & 59 & 59 & 0.937 \\
\hline Buprenorphine & 100 & 60 & 70 & 0.24 \\
\hline Tramadol & 39 & 48 & 29 & 0.25 \\
\hline \multicolumn{5}{|l|}{ Amphetamines } \\
\hline Total & 45 & 56 & 71 & 0.184 \\
\hline \multicolumn{5}{|l|}{ Medicine } \\
\hline Total & 45 & 43 & 37 & 0.4318 \\
\hline Acetaminophen & 23 & 41 & 36 & 0.694 \\
\hline Tricyclic antidepressant & 47 & 61 & 38 & 0.458 \\
\hline Benzodiazepine & 40 & 45 & 40 & 0.956 \\
\hline Antipsychotic & 60 & 50 & 55 & 0.458 \\
\hline Antihistamines & 57 & 45 & 30 & 0.345 \\
\hline \multicolumn{5}{|l|}{ Others } \\
\hline Total & 58 & 41 & 50 & 0.4075 \\
\hline Carboxyhemoglobin & 33 & 20 & 37 & 0.237 \\
\hline Pesticide & 40 & 50 & 40 & 0.943 \\
\hline Envenomation & 69 & 45 & 75 & 0.404 \\
\hline Plant & 60 & 60 & 75 & 0.975 \\
\hline \multicolumn{5}{|l|}{ Total } \\
\hline Total & 53 & 54 & 51 & 0.632 \\
\hline
\end{tabular}

${ }^{\mathrm{a}}$ Data were analyzed by $\chi^{2}$.

to abstain from activities associated with procurement and administration of the abused opioid, but also eliminates much of the morbidity and mortality associated with illicit drug abuse (23). Due to the establishment of a large number of outpatient drug recovery clinics for MMT in Mashhad in recent years, that let patients taking drugs especially methadone syrup home, a larger amount of this opiate is available at homes $(21,24)$. In recent years, to prevent methadone abuse through illegal selling and to improve patients' compliance, methadone provision has been changed from pills to syrup in this area; therefore, it might induce more pediatric poisoning. Lack of knowledge about methadone and its side effects may have affected the rate of pediatric poisoning. Also, high doses in syrup $(5 \mathrm{mg} / \mathrm{mL})$ can be more toxic for children (18). Furthermore, home storage of drugs in inappropri- ate containers, such as juice containers or baby bottles, may be a cause of accidental methadone ingestion by children. Administration of methadone syrup instead of safe drugs such as acetaminophen or diphenhydramine syrup by parents to children may also cause over dosages (24). Such events can be anticipated because methadone is frequently formulated as a palatable liquid and may not be distributed in child resistant containers. Unfortunately, children death by methadone poisoning is frequent (2426).

As the pattern of methadone pediatric poisoning has changed through 2011 - 2013 in this area, we focused on the geographic location of the patients in the city. There are 13 municipal divisions in Mashhad. We investigated the rate of pediatric poisoning with methadone in each municipal division per one million civilians. We found 


\begin{tabular}{|c|c|c|c|c|}
\hline Cause of Intoxication & 2011 & 2012 & 2013 & PValue $^{\text {b }}$ \\
\hline \multicolumn{5}{|l|}{ Opium and opiate } \\
\hline Total & $357(68.8)$ & $326(69.1)$ & $445(62.7)$ & $0.0269^{c}$ \\
\hline Opium & $179(34.5)$ & $135(28.6)$ & $117(16.5)$ & $<0.0001^{\mathrm{C}}$ \\
\hline Methadone & $144(27.7)$ & $159(33.7)$ & $252(35.5)$ & $0.0303^{*}$ \\
\hline Buprenorphine & $6(1.2)$ & $5(1.1)$ & $18(2.5)$ & 0.081 \\
\hline Tramadol & $28(5.4)$ & $27(5.7)$ & $58(8.2)$ & 0.0994 \\
\hline \multicolumn{5}{|l|}{ Amphetamines } \\
\hline Total & $11(2.1)$ & $16(3.4)$ & $20(2.8)$ & 0.4729 \\
\hline \multicolumn{5}{|l|}{ Medicine } \\
\hline Total & $109(21.0)$ & $96(20.3)$ & $209(29.4)$ & $0.0002^{c}$ \\
\hline Acetaminophen & $21(4.0)$ & $17(3.6)$ & $46(6.5)$ & $0.0436 \mathrm{c}$ \\
\hline Tricyclic antidepressant & $17(3.3)$ & $13(2.8)$ & $26(3.7)$ & 0.6927 \\
\hline Benzodiazepine & $59(11.4)$ & $53(11.2)$ & $105(14.8)$ & 0.1042 \\
\hline Antipsychotic & $5(1.0)$ & $2(0.4)$ & $9(1.3)$ & 0.3377 \\
\hline Antihistamines & $7(1.3)$ & $11(2.3)$ & $23(3.2)$ & 0.1016 \\
\hline \multicolumn{5}{|l|}{ Others } \\
\hline Total & $36(6.9)$ & $31(6.6)$ & $31(4.4)$ & 0.1091 \\
\hline Carboxyhemoglobin & $3(0.6)$ & $6(1.3)$ & $8(1.1)$ & 0.4966 \\
\hline Pesticide & $5(1.0)$ & $4(0.8)$ & $5(0.7)$ & 0.6166 \\
\hline Envenomation & $13(2.5)$ & $11(2.3)$ & $14(2.0)$ & 0.5247 \\
\hline Plant & $15(2.9)$ & $10(2.1)$ & $4(0.6)$ & $0.0015^{c}$ \\
\hline \multicolumn{5}{|l|}{ Total } \\
\hline Total & $519(100.0)$ & $472(100.0)$ & $710(100.0)$ & \\
\hline
\end{tabular}

${ }^{\mathrm{a}}$ Values are expressed as No. (\%).

${ }^{\mathrm{b}}$ Data were analysis by $\chi^{2}$ test.

${ }^{\mathrm{c}}$ Statistically significant.

that the zone of high incidence of methadone intoxication changed from the first and second municipal divisions, which are recognized as high economic areas, to $7^{\text {th }}$ municipal division, as a low economic area (Figure 1 and Table 5). This may show the variation of socioeconomic level in parents, the change in addiction pattern, the change in geographical distribution of abstinence therapy clinics, and possible other types of addiction. Also, it may be due to the variation in population pattern e.g. number of children.

\subsection{Conclusion}

Pediatric poisonings increased during 2011 - 2013 in Mashhad, Iran. The pattern of APP changed from traditional opium poisoning in 2011 to methadone poisoning in 2013. Also, the mean age of APP changed during this period. Methadone poisoning is now the most common type of pediatric poisoning (35\%) in this area that may be due to the availability of unsafe form of the drug (syrup) for children. Methadone poisoning was more significant in the poor economic areas of the city. The changing pattern of pediatric poisoning over the years is probably due to the changing pattern of addiction from opium to its synthetic derivatives such as methadone and increasing its availability at the homes of addicted parents.

More investigations, particularly a prospective epidemiological study, are necessary to develop a health plan of action to control pediatric poisoning in this area.

\subsection{Limitations}

The exact population of children and fertility rates in each municipal division of Mashhad through 2011 - 2013 was not found, so the estimated 2012 population of every 
Table 5. The Number of Methadone Poisoned Children per One Million Citizens in Each Municipal Division of Mashhad (2011 - 2013)

\begin{tabular}{|c|c|c|c|c|c|}
\hline \multirow{2}{*}{$\begin{array}{l}\text { Municipal } \\
\text { Division } \\
\text { of } \\
\text { Mashhad }\end{array}$} & \multirow[t]{2}{*}{ Estimated 2012 Population Size } & \multicolumn{3}{|c|}{ Number of Poisoning/One Million Persons } & \multirow[t]{2}{*}{ P value } \\
\hline & & 2011 & 2012 & 2013 & \\
\hline 1 & 172547 & 75.3 & 58.0 & 23.2 & 0.0479 \\
\hline 2 & 422166 & 37.9 & 4.7 & 21.3 & 0.0043 \\
\hline 3 & 338866 & 38.4 & 35.4 & 26.6 & 0.6822 \\
\hline 4 & 243331 & 37.0 & 16.4 & 16.4 & 0.2298 \\
\hline 5 & 156640 & 0.0 & 0.0 & 0.0 & 1 \\
\hline 6 & 196248 & 35.7 & 20.4 & 51.0 & 0.2764 \\
\hline 7 & 216580 & 4.6 & 36.9 & 23.1 & 0.0712 \\
\hline 8 & 103261 & 19.4 & 96.8 & 9.7 & 0.0036 \\
\hline 9 & 253711 & 0.0 & 7.9 & 0.0 & 0.1353 \\
\hline 10 & 215686 & 32.5 & 46.4 & 27.8 & 0.5682 \\
\hline 11 & 170945 & 23.4 & 17.5 & 0.0 & 0.1561 \\
\hline 12 & 20530 & 0.0 & 0.0 & 0.0 & 1 \\
\hline 13 & 32330 & 247.4 & 309.3 & 309.3 & 0.8668 \\
\hline
\end{tabular}

municipal division was used as denominator to calculate all the rates.

\section{Acknowledgments}

Authors would like to thank the stuffs of pediatric wards of Imam Reza Hospital for their cooperation and also manager of Hospital Information System (HIS) of Imam Reza Hospital for their assistance to access to data of admitted poisoned children.

\section{Footnote}

Authors' Contribution: Anahita Alizadeh and Masoumeh Zheani Asoudeh deigned the study and collected data, Fatemeh Abdi analyzed the data, Mohammad Moshiri reanalyzed the data, Anahita Alizadeh and Mohammad Moshiri wrote the first draft of manuscript, Mahdi Balali Mood and Leila Etemad finalized the manuscript and Leila Etemad submitted the files and she is corresponding author.

\section{References}

1. Sadeghi-Bojd S, Khajeh A. Chronological variations of children poisoning causes in zahedan, South of iran. Int J High Risk Behav Addict. 2014;3(3):e19223. doi: 10.5812/ijhrba.19223. [PubMed: 25632384].

2. Sahin S, Carman KB, Dinleyici EC. Acute poisoning in children; data of a pediatric emergency unit. Iran J Pediatr. 2011;21(4):479-84. [PubMed: 23056835].
3. Fine JS. Pediatric principle. MC Graw Hill; 2011. pp. 447-61.

4. O Donell KA, Ewald MB. Poisoning. Philadelphia: Elsevier, Saunders; 2011. pp. 251-2.

5. Lovegrove MC, Mathew J, Hampp C, Governale L, Wysowski DK, Budnitz DS. Emergency hospitalizations for unsupervised prescription medication ingestions by young children. Pediatrics. 2014;134(4):1009-16. doi: 10.1542/peds.2014-0840. [PubMed: 25225137].

6. Fallahzadeh M, Salehi A, Hassanzadeh J, Fallahzadeh MH. Epidemiological Aspects of Acute Poisoning in Children Admitted to a Referral Hospital During a Six-Year-Period. Ann Pediatr Child Health. 2014;2(3):1020.

7. Haghighat M, Moravej H, Moatamedi M. Epidemiology of Pediatric Acute Poisoning in Southern Iran: A Hospital-Based Study. Bull Emerg Trauma. 2013;1(1):28-33. [PubMed: 27162818].

8. Lifshitz M, Gavrilov V. Acute poisoning in children. Isr Med Assoc J. 2000;2(7):504-6. [PubMed:10979321].

9. Vasavada DH, Desai DP. Clinical Profile And Outcome Of Children Presenting With Poisoning (A Hospital Based Study). National J Integrated Res Med. 2013;4(4):1-7.

10. Soori H, Naghavi M. Childhood deaths from unintentional injuries in rural areas of Iran. Inj Prev. 1998;4(3):222-4. doi: 10.1136/ip.4.3.222. [PubMed: 9788095].

11. Mehrpour O, Sharifi MD, Ebrahimi M. Pattern of Acute Pediatric Poisonings in Birjand City, East of Iran. Int J Med Toxicol Forensic Med. 2015;5(4):192-200.

12. Hassan BA, Siam MG. Patterns of Acute Poisoning in Childhood in Zagazig, Egypt: An Epidemiological Study. Int Scholarly Res Notices. 2014;2014 doi: 10.1155/2014/245279.

13. Ocan M, Bbosa GS, Waako P, Ogwal-Okeng J, Obua C. Factors predicting home storage of medicines in Northern Uganda. BMC Public Health. 2014;14:650. doi:10.1186/1471-2458-14-650. [PubMed: 24964746].

14. Ruhm CJ. Drug poisoning deaths in the United States, 1999-2012: a statistical adjustment analysis. Popul Health Metr. 2016;14:2. doi: 10.1186/s12963-016-0071-7. [PubMed: 26778921]. 
15. Singh D, Jit I, Tyagi S. Changing trends in acute poisoning in Chandigarh zone: a 25-year autopsy experience from a tertiary care hospital in northern India. Am J Forensic Med Pathol. 1999;20(2):203-10. [PubMed: 10414665].

16. Joghataee H, Mirakbari S, Moosavi S, Farnaghi F. Poisoning in Children: a study of 1120 poisoned patients younger than 12 years at Loghman Hakeem poison control center, Tehran, Iran, 2000-2001. Internet JPediatr Neonatol. 2001;2(2):1-7.

17. Farnaghi F, Jafari N, Mehregan FF. Methadone poisoning among children referred to Loghman-Hakim Hospital in 2009 [in Persian]. Pajouhandeh. 2012;16:299-303.

18. Paulozzi L, Jones C, Mack K, Rudd R, Centers for Disease Control and Prevention (CDC). Vital Signs: Overdoses of Prescription Opioid Pain Relievers and Other Drugs Among Women - United States, 1999-2010, Morbidity and Mortality Weekly Report(MMWR) 2013. Available from: https://www.cdc.gov/mmwr/preview/mmwrhtml/mm6226a3.htm.

19. Binchy JM, Molyneux EM, Manning J. Accidental ingestion of methadone by children in Merseyside. BMJ. 1994;308(6940):1335-6. doi: 10.1136/bmj.308.6940.1335. [PubMed: 8019221].

20. Martin TC, Rocque MA. Accidental and non-accidental ingestion of methadone and buprenorphine in childhood: a single center experience, 1999-2009. Curr Drug Saf. 2011;6(1):12-6. doi: 10.2174/157488611794480034. [PubMed: 21047302].
21. Shadnia S, Rahimi M, Hassanian-Moghaddam H, Soltaninejad K, Noroozi A. Methadone toxicity: comparing tablet and syrup formulations during a decade in an academic poison center of Iran. Clin Toxicol (Phila). 2013;51(8):777-82. doi: 10.3109/15563650.2013.830732. [PubMed: 23972442].

22. Bart G. Maintenance medication for opiate addiction: the foundation of recovery. J Addict Dis. 2012;31(3):207-25. doi: 10.1080/10550887.2012.694598. [PubMed: 22873183].

23. Subedi B, Kannan K. Mass loading and removal of select illicit drugs in two wastewater treatment plants in New York State and estimation of illicit drug usage in communities through wastewater analysis. Environ Sci Technol. 2014;48(12):6661-70. doi: 10.1021/es501709a. [PubMed: 24865581].

24. Maamouri GA, Alizadeh-Ghamsari A, Teimouri E. Evaluation of methadone poisoning in hospitalized children: a short review. Int J Ped. 2014;2:65-7.

25. Jabbehdari S, Farnaghi F, Shariatmadari SF, Jafari N, Mehregan FF, Karimzadeh P. Accidental children poisoning with methadone: an Iranian pediatric sectional study. Iran J Child Neurol. 2013;7(4):32-4. [PubMed: 24665315].

26. Ghorbani F, Salimkhani N, Pakdel S, Rahkar Farshi M. Methadone Poisoning in Children and some Factors affecting it: A Cross-sectional Study in Tabriz, Northwest of Iran. Int J Pediatr. 2015;3(4,1):725-31. 